\title{
Spatial patterns of fetal mortality: scenario before and after the implementation of surveillance
}

Maria Carolina Lyra da Silva 1

(iD) https://orcid.org/0000-0002-5202-1300

Conceição Maria de Oliveira 2

(iD) https://orcid.org/0000-0002-2220-5782

Amanda Priscila de Santana Cabral Silva 3

D https://orcid.org/0000-0003-2337-9925

Cristine Vieira do Bonfim 4

(iD) https://orcid.org/0000-0002-4495-9673

1,2 Secretaria de Saúde do Recife. Recife, PE, Brasil.

3 Centro Acadêmico de Vitória. Universidade Federal de Pernambuco. Vitória de Santo Antão PE, Brasil.

4 Diretoria de Pesquisas Sociais. Fundação Joaquim Nabuco. Rua Dois Irmãos, 92. Ed. Anexo Anízio Teixeira. Recife, PE, Brasil. CEP: 52.071-440.

E-mail: cristine.bonfim@uol.com.br

\begin{abstract}
Objectives: to analyze the spatial distribution of fetal deaths before and after implementation of surveillance for this event in the city of Recife, in the Northeast Region of Brazil.

Methods: an ecological study whose spatial analysis unit was the 94 neighborhoods. The gross fetal mortality rates were calculated and the local empirical Bayesian estimator was adopted to smooth out random fluctuations of such rates. To analyze the spatial autocorrelation, the Global Moran's Index was used, and spatial clusters were located by the Local Moran's Index.

Results: during the period before implementation of death surveillance, 1,356 fetal deaths were reported, a coefficient of 9.9 deaths per thousand births. During the second period, 1,325 fetal deaths occurred, a coefficient of 9.6 deaths per thousand births. The Global Moran's Indexes (I) were $I=0.6$ and $I=0.4$ for the first and second periods, respectively, with statistical significance $(p<0.05)$. For both periods analyzed, spatial clusters of high-risk neighborhoods were identified in the northern and eastern regions of the city.

Conclusion: the spatial analysis indicated areas that persist as priorities for planning surveillance and health assistance actions to reduce fetal mortality.

Key words Fetal mortality, Spatial analysis, Fetal death, Vital statistics
\end{abstract}

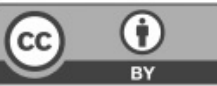




\section{Introduction}

Fetal mortality is an indicator that reflects the quality of women's healthcare during pregnancy and labor. The Millennium Development Goals (MDGs) contributed to boosting the reduction in maternal mortality and of children under the age of five, during the period from 2003 to 2015, in the world. Fetal mortality rates (FMRs), in their turn, have decreased more slowly, since 2000, compared to the maternal mortality and that of children under the age of five. As of 2015 , it was estimated that 2.6 million fetal deaths occur annually in the world, almost all (98\%) in low- and medium-income countries. ${ }^{1}$

Historically, fetal deaths have not been incorporated into global mortality estimates and, even with the recent efforts to include them, fetal mortality rate is still underestimated. 2 Social stigma and misclassification, such as miscarriage or early neonatal deaths, are factors that contribute to this fact. 2

Nowadays, the reduction in fetal deaths is established in the Every Newborn Action Plan of the World Health Organization, which aims to provide equitable quality healthcare for all women and newborns and targets $\leq 12$ stillbirths per thousand births until 2030.3 To monitor the progress of the plan, accurate data are required and may help to prepare policies and monitor fetal mortality. 2 The plan suggests the implementation of national perinatal mortality surveillance systems that record all deaths and their causes, in addition to the identification of contextual and maternal factors that may contribute to reducing preventable deaths. 4 Countries (the United Kingdom, New Zealand, and the Netherlands) that implemented this surveillance evidenced a reduction in stillbirth mortality rate. 5

Infant and fetal death surveillance is a strategy that enables the analysis of the causes and circumstances involved in the occurrence of these events and of the healthcare quality, in addition to contributing to improvements of vital statistics. ${ }^{6}$ In Brazil, in 2010, the mandatory infant and fetal death surveillance was established for the healthcare services of the Unified Health System (SUS). ${ }^{7}$

The city of Recife was one of the first places in the country to implement infant and fetal death surveillance, even before the Ministry of Health made it mandatory, and it keeps operating continuously. This surveillance has the purpose of identifying healthcare failures to support strategic preventive actions, changes in work processes, and the organization of the maternal and child healthcare line. 8 Accordingly, the impact of the death surveillance system on the reduction in fetal deaths becomes clear. This study aimed at analyzing the spatial distribution of fetal deaths before and after implementation of surveillance for this event in Recife, Pernambuco.

\section{Methods}

This is an ecological study carried out in the city of Recife, Pernambuco. In 2010, the city had 1,537,704 inhabitants and, of these, 19,142 were under the age of one. Recife is an urban city, with a heterogeneous occupation pattern, with highly valued areas and other areas with structural problems. Its territorial composition is diversified (hills $-67.43 \%$, plains $23.26 \%$, and water areas $-9.31 \%$ ). It has 94 neighborhoods grouped into eight health districts (HD) and six Political-Administrative Regions (RPA Portuguese acronym) (Figure 1). HD VI concentrates $29.1 \%$ of the population. The Local Human Development Index was 0.772 , which is the second best in the state. Approximately $33 \%$ of the population has no income or earns up to one minimum wage. Almost $40 \%$ of the population has no education or has not completed Primary and Lower Secondary Education. 9

In Recife, fetal death surveillance is operationalized based on the identification of deaths, followed by epidemiological investigation (in household, outpatient, and hospital settings), discussion about the deaths (with healthcare, surveillance, and management professionals), and, finally, submission of proposals for promotion, health care, and correction of vital statistics. ${ }^{8}$ Fetal deaths weighing $>2,000 \mathrm{~g}$ or caused by the following maternal conditions: syphilis, infection by human immunodeficiency virus (HIV) or Acquired Immunodeficiency Syndrome (AIDS), diabetes, hypertension, and urinary tract infection are prioritized for investigation and discussion. The proportion of fetal deaths investigated and discussed in the municipality ranged from $12.5 \%$ (2011) to $68.5 \%$ (2016).

All fetal deaths (weight $\geq 500 \mathrm{~g}$ and/or gestational age $\geq 22$ weeks) reported in Recife neighborhoods were analyzed. Data were obtained from the Mortality Information System (SIM - Portuguese acronym) and the Live Birth Information System (Sinasc - Portuguese acronym), provided by the Health Department of Recife, for calculation of the fetal mortality rate. In Recife, the coverage and quality of Sinasc and SIM are adequate, enabling the direct calculation of the coefficients. 10

Two periods of study were considered: before the implementation of fetal death surveillance (20042009) and after its implementation (2011-2016). The 


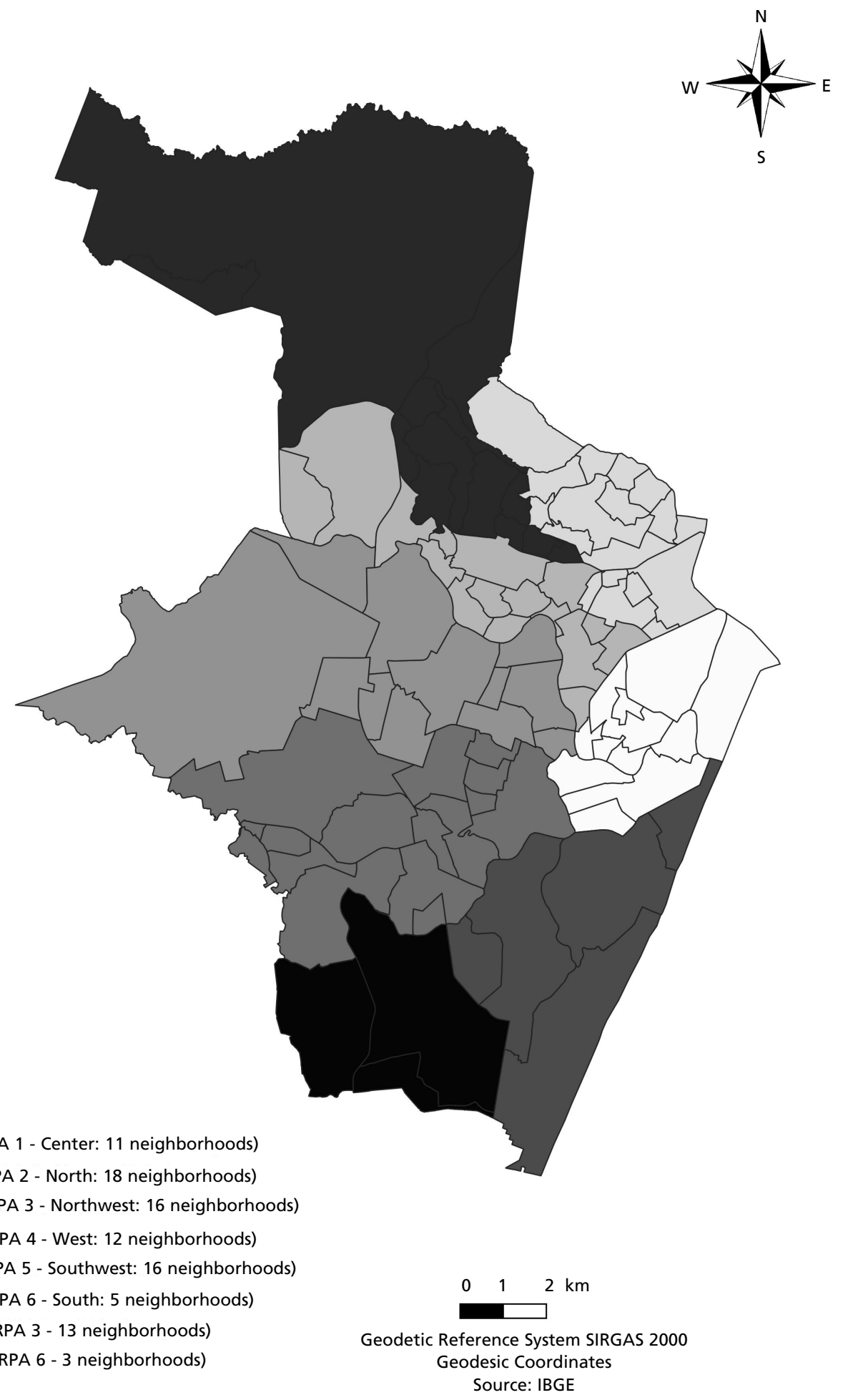


year of 2010, when infant and fetal death surveillance became mandatory, was excluded from the analysis. The neighborhood was adopted as an analysis unit due to the easy implementation by the management and administration of the municipal health system.

Gross fetal mortality rates were calculated for both periods. For the neighborhoods, considering that small populations and/or underreporting may cause variability in gross rates, local empirical Bayesian estimator was used to smooth out the estimated coefficients calculated for small geographic areas, eliminating random fluctuations not associated with mortality. ${ }^{11}$ The presence of spatial autocorrelation of the smoothed coefficients was investigated by calculating the Global Moran's Index (GMI). This index ranges from minus one to one, and the values close to zero indicate the absence of spatial correlation. The GMI was classified as weak $(<0.3)$, moderate $(0.3-0.7)$, or strong $(>0.7)$, as used in the evaluation of Pearson correlation. 12

The Local Moran's Index was analyzed to identify the spatial clusters. The Moran scatterplot, represented in BoxMAP, was applied, and the resulting quadrants were interpreted as follows: Q1 (region composed of neighborhoods with high mortality rates, surrounded by neighborhoods with high mortality rates); Q2 (region composed of neighborhoods with low mortality rates, surrounded by neighborhoods with low mortality rates); Q3 (region composed of neighborhoods with high mortality rates, surrounded by neighborhoods with low mortality rates); and Q4 (region composed of neighborhoods with low mortality rates, surrounded by neighborhoods with high mortality rates). ${ }^{13}$ Finally, the MoranMap was obtained, representing the special clusters with statistical significance equal to or of less than 5\%.13 Areas classified as Q1 were deemed to be priority areas for fetal death surveillance.

Spatial analysis was performed using TerraView, version 4.2.0. The base map of Recife neighborhoods was obtained from the census tract database of the Brazilian Institute of Geography and Statistics (IBGE - Portuguese acronym). ${ }^{14}$

The project was approved by the Human Research Ethics Committee of the Institute of Integrative Medicine Prof. Fernando Figueira (CAEE 82816018.1.0000.5201).

\section{Results}

Between 2004 and 2009, the period before the implementation of death surveillance, 1,356 fetal deaths (with 52 deaths [3.7\%] due to lack of information on the neighborhood of residence) were reported, which characterizes a FMR of 9.9 deaths per thousand births in Recife (Table 1). Of the 94 neighborhoods, 73 (77.6\%) presented a FMR higher than the municipal average, and the highest rates, higher than 11.3 deaths per thousand births, were identified in the north, west, and east regions (Figure 2A). The moderate global spatial autocorrelation was confirmed $(\mathrm{GMI}=0.6 ; p=0.001)$, while local spatial autocorrelation ratified those regions already indicated by the Bayesian estimator through Q1 (Figures 2B and 2C).

In the second period (2011-2016), after the implementation of surveillance, 1,325 fetal deaths occurred (excluding 37 deaths, $2.7 \%$, with no record of neighborhood of residence), making a CMF of 9.6 deaths per thousand births (Table 1). In 55 (58.5\%) of the 94 neighborhoods, the FMR was higher than the municipal average (Figure 2D). The moderate spatial autocorrelation was maintained ( $\mathrm{I}=0.4$; $\mathrm{I}=$ $0.4 ; p=0.001)$ and, at the local level, statistically significant Q1 clusters continued to be observed in the far north and east regions of the city (Figure $2 \mathrm{E}$ and $2 \mathrm{~F}$ ).

\section{Discussion}

A reduction in the fetal mortality ratio from 9.9 to 9.6 deaths per thousand births was observed, following the national trend, 15 different from the infant mortality rate, which showed a significant decrease, strongly influenced by improvements in healthcare policies, intersectoral actions, and implementation of strategies such as death surveillance. 16 This may be a reflex of the low visibility of fetal deaths, which were not contemplated in international agreements, in addition to not being the focus of public policies. 1,6

Q1 regions were identified throughout the study period, regions that are characterized by high fetal mortality rates and are a surveillance priority. However, comparing the second study period to the first, a decrease in the number of Q1 neighborhoods was observed, with emphasis on the disappearance of the cluster located in the western part of the city. This may be a reflex of the implementation of fetal death surveillance, as its actions include the identification of situations of social vulnerability and failures in the network of services and healthcare that strongly influence the occurrence of deaths. 6,8

However, the neighborhoods in the far northern and eastern region maintained their classification as Q1. These are regions characterized by poor living 
Distribution of fetal deaths of mothers residing in Recife. Recife, PE, Brazil, 2004-2009 and 2011-2016.

\begin{tabular}{|c|c|c|c|c|c|c|}
\hline \multirow[t]{2}{*}{ Year } & \multirow[t]{2}{*}{ LB } & \multirow[t]{2}{*}{$\begin{array}{l}\text { Number of } \\
\text { fetal deaths }\end{array}$} & \multicolumn{2}{|c|}{$\begin{array}{l}\text { Number of fetal deaths with } \\
\text { information on the } \\
\text { neighborhood of residence* }\end{array}$} & \multicolumn{2}{|c|}{$\begin{array}{l}\text { Fetal mortality rate } \\
\text { (per thousand births) }\end{array}$} \\
\hline & & & Year & Aggregate & Year & Aggregate \\
\hline 2004 & 22734 & 257 & 255 & & 11.1 & \\
\hline 2005 & 23109 & 272 & 272 & & 11.6 & \\
\hline 2006 & 22862 & 209 & 204 & & 8.8 & \\
\hline 2007 & 22043 & 187 & 185 & 1,356 & 8.3 & 9.9 \\
\hline 2008 & 22034 & 240 & 221 & & 9.9 & \\
\hline 2009 & 22506 & 243 & 219 & & 9.6 & \\
\hline 2010 & 21787 & 190 & 186 & - & 8.5 & - \\
\hline 2011 & 22252 & 232 & 221 & & 9.8 & \\
\hline 2012 & 22642 & 227 & 206 & & 9.0 & \\
\hline 2013 & 23187 & 235 & 235 & & 10.0 & \\
\hline 2014 & 23516 & 228 & 225 & 1,325 & 9.5 & 9.6 \\
\hline 2015 & 23663 & 221 & 219 & & 9.2 & \\
\hline 2016 & 21390 & 219 & 219 & & 10.1 & \\
\hline
\end{tabular}

*89 (3.2\%) fetal deaths were excluded due to lack of information on the mother's neighborhood of residence, being $52(3.7 \%)$ in the first period (2004-2009) and $36(2.7 \%)$ in the second period (2011-2016).

and infrastructure conditions that concentrate lowerincome population groups and significant social inequalities. 9 The neighborhoods in the north region are characterized by intense verticalization of the plain area and by a high area (hills), occupied by the most socially vulnerable population. A recent spatial analysis of infant and fetal mortality in Recife and its connection to social deprivation identified clusters of areas with poor living conditions in the northern and western regions. 17 In another study, the same areas had the worst prenatal care indicators. 18

The analysis of fetal mortality and the social determinants of health has shown spatial patterns associated with the inequalities between the regions, economic positions, and accessibility to prenatal care. In other words, fetal mortality was associated with the uneven social circumstance in which people live. 19

Proper prenatal care favors the early diagnosis and treatment of countless complications and enables health education to mitigate risk behaviors, contributing to a decrease in fetal, infant, and maternal mortality. The improved quality of prenatal care is important to maximize maternal health and fetal well-being and is strongly associated with lower rates of fetal deaths. ${ }^{1}$

Spatial analysis, through the Bayesian estimate and subsequent analysis for global and local spatial autocorrelation, enabled the identification of priority areas for surveillance actions. In addition to the exploratory use, through other techniques, it enables the identification of associated factors and helps to direct the strategies in the territory to control the problem.

The availability of free computer programs such as TerraView and QGis, and of cartographic databases made available by the Brazilian Institute of Geography and Statistics (IBGE) allow the incorporation of geographic information systems in the routine of healthcare services, especially in health surveillance actions.

This study has some limitations: 1) regarding the study design, the ecological fallacy is apparently inherent; 2) the use of secondary data, which may contain filling errors and underreporting; 3) the neighborhood as a spatial analysis unit may hide its internal inequalities, which could be more evidenced in smaller units, for example the census tract. Considering the neighborhood as an analysis unit, it is not possible to conclude that the fetal mortality rates are homogeneously distributed; 4) fetal death variables, available in SIM, which could help reduce fetal mortality, were not analyzed. Despite these limitations, the spatial differences in fetal mortality rates evidenced in the results of the study may contribute to death surveillance actions in Recife.

Changes observed in the spatial patterns of fetal deaths after the implementation of surveillance may be a reflex of the interventions generated by the strategy. The use of geoprocessing has enabled the 
Spatial distribution of fetal mortality. Recife, PE, Brazil. (A) Fetal mortality coefficient estimated by the Bayesian method (per thousand births), (B) BoxMAP and (C) MoranMAP, 2004 to 2009; (D) Fetal mortality coefficient by the Bayesian method (per thousand births), (E) BoxMAPand (F) MoranMAP, 2011 to 2016.
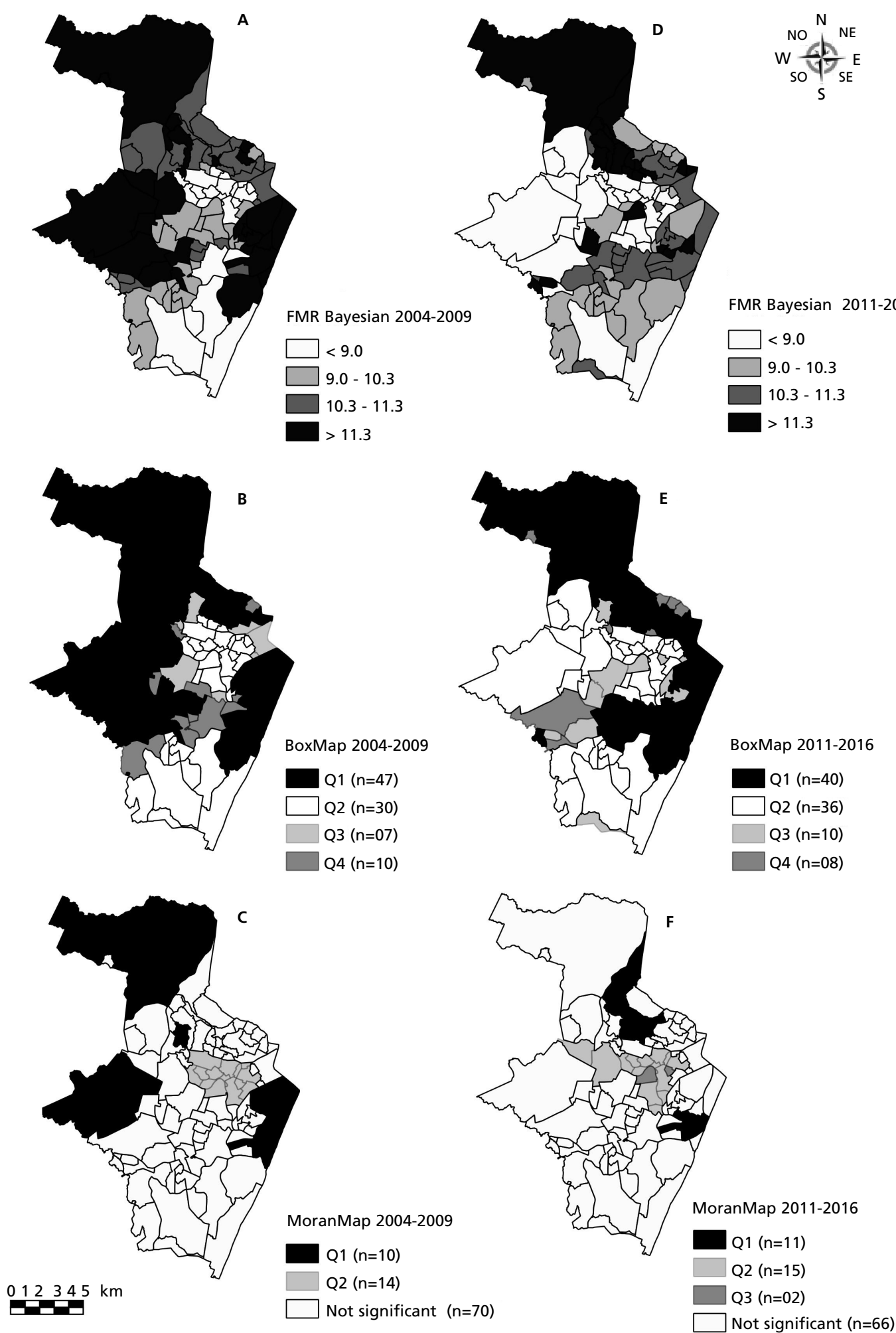
identification of territorial differences and signaled the priority areas in the planning of actions for enhancement of surveillance and healthcare, aiming at the decrease in fetal mortality.

\section{Authors' contribution}

Silva MCL and Oliveira CM: Conception and design of the study, bibliographic survey, data analysis and interpretation, paper writing, and final approval of

\section{References}

1. Lawn JE, Blencowe H, Waiswa P, Amouzou A, Mathers C, Hogan D, et al. Stillbirths: rates, risk factors, and acceleration towards 2030. Lancet. 2016; 387 (10018): 587-603.

2. McClure EM. Enhancing routine surveillance to improve stillbirth data. Lancet Glob Health. 2020; 8 (4): e464-5.

3. WHO (World Health Organization). Every newborn: An action plan to end Preventable deaths: Executive summary. Geneva; 2014 [cited 2020 Aug 10]. Available from: https://www.who.int/maternal_child_adolescent/newborns/ every-newborn/en/

4. Po’ G, Monari F, Zanni F, Grandi G, Lupi C, Facchinetti F, Stillbirth Emilia-Romagna Audit Group. A regional audit system for stillbirth: a way to better understand the phenomenon. BMC Pregnancy Child. 2019; 19 (1): 276.

5. Norris T, Manktelow BN, Smith LK, Draper ES. Causes and temporal changes in nationally collected stillbirth audit data in high-resource settings. Semin Fetal Neonatal Med. 2017; 22 (3): 118-28.

6. Helps A, Leitao S, Greene R, O'Donoghue K. Perinatal mortality audits and reviews: Past, present and the way forward. Eur J Obstet Gynecol Reprod Biol. 2020 July, 250: 24-30.

7. Brasil. Ministério da Saúde. Gabinete do Ministro. Portaria $\mathrm{n}^{\mathrm{o}} 72$, de 11 de janeiro de 2010. Estabelece que a vigilância do óbito infantil e fetal é obrigatória nos serviços de saúde (públicos e privados) que integram o Sistema Único de Saúde (SUS). Brasília, DF; 2010 [cited 2020 Aug 10]. Available from: http://bvsms.saude.gov.br/bvs/saudelegis/ gm/2010/prt0072_11_01_2010.html

8. Oliveira CM, Bonfim CV, Guimarães MJB, Frias PG, Antonino VCS, Medeiros ZM. Infant mortality surveillance in Recife, Pernambuco, Brazil: operationalization, strengths and limitations. Epidemiol Serv Saúde. 2017; 26 (2): 413-9.

9. Prefeitura Municipal de Recife. Plano Municipal de Saúde 2014-2017 [Internet]. Recife: Prefeitura Municipal; 2014 [cited 2020 Aug 10]. Available from: http://www2.recife.pe.gov.br/servico/plano-municipal-desaude-pms-2014-2017 the version to be submitted. Silva APSC and Bonfim CV: Data analysis and interpretation, paper writing, critical review of relevant intellectual content, and final approval of the version to be submitted. All the authors have approved the final version of the document.

10. Rodrigues M, Bonfim C, Portugal JL, Frias PG, Gurgel IGD, Costa TR, et al. Spatial analysis of infant mortality and the adequacy of vital information: a proposal for defining priority areas. Ciênc Saúde Coletiva. 2014; 19 (7): 2047-54.

11. Assunção RM, Barreto SM, Guerra HL, Sakurai E. Maps of epidemiological rates: a Bayesian approach. Cad Saúde Pública. 1998; 14 (4): 713-23.

12. Vale D, Morais CMM, Pedrosa LFD, Ferreira MÂF, Oliveira ÂGRC, Lyra CO. Spatial correlation between excess weight, purchase of ultra-processed foods, and human development in Brazil. Ciênc Saúde Coletiva. 2019; 24 (3): 983-96.

13. Monteiro AMV, Câmara G, Carvalho MS, Druck S. Análise espacial de dados geográficos. Brasília, DF: EMBRAPA; 2004.

14. Ministério do Planejamento, Orçamento e Gestão (BR), Instituto Brasileiro de Geografia e Estatística. Cartas e mapas [Internet]. Rio de Janeiro: IBGE; 2014 [cited 2020 Sep 21] Available from: https://portaldemapas.ibge.gov.br/ portal.php\#homepage

15. Vieira MSM, Vieira FM, Fröde TS, d'Orsi E. Fetal Deaths in Brazil: Historical Series Descriptive Analysis 19962012. Matern Child Health J. 2016; 20 (8): 1634-50.

16. Oliveira CM, Bonfim CV, Guimarães MJB, Frias $\mathrm{PG}$, Medeiros ZM. Infant mortality: temporal trend and contribution of death surveillance. Acta Paul Enferm. 2016; 29 (3): $282-90$

17. Bonfim CV, Silva APSC, Oliveira CM, Vilela MBR, Freire NCF. Spatial analysis of inequalities in fetal and infant mortality due to avoidable causes. Rev Bras Enferm. 2020; 73 (Suppl. 4): e20190088.

18. Holanda ER, Galvão MTG, Pedrosa NL, Paiva SS, Almeida RLF. Spatial analysis of infection by the human immunodeficiency virus among pregnant women. Rev Latino-Am Enferm. 2015; 23 (3): 441-9.

19. Adeyinka DA, Olakunde BO, Muhajarine N. Evidence of health inequity in child survival: spatial and Bayesian network analyses of stillbirth rates in 194 countries. Sci Rep. 2019; 9 (1): 19755

Received on July 24, 2020.

Final version presented on June 21, 2021.

Approved on July 19, 2021. 